Dusseljee, J.C.E., Rijken, P.M., Cardol, M., Groenewegen, P.P., Curfs, L.M.G. Participation in daytime activities among people with mild or moderate intellectual disability. Journal of Intellectual Disability Research: 2011, 55(1), 4-18

\begin{tabular}{|l|l|}
\hline Postprint Version & 1.0 \\
\hline Journal website & http://onlinelibrary.wiley.com/doi/10.1111/j.1365-2788.2010.01342.x/abstract \\
\hline Pubmed link & http://www.ncbi.nlm.nih.gov/pubmed/21029235 \\
\hline DOI & $10.1111 / \mathrm{j} .1365-2788.2010 .01342 . \mathrm{x}$ \\
\hline
\end{tabular}

\title{
Participation in daytime activities among people with mild or moderate intellectual disability
}

\author{
J. C. E. DusSELJEE ${ }^{1, *}$, P. M. RIJKEN ${ }^{1}$, M. CARDOL ${ }^{1}$, L. M. G. CURFS ${ }^{2}$, P. P. GROENEWEGEN ${ }^{1,3}$ \\ ${ }^{1}$ NIVEL, Netherlands Institute for Health Services Research, Utrecht, The Netherlands \\ ${ }^{2}$ Department of Clinical Genetics, Maastricht University Medical Centre, Maastricht/Governor Kremers \\ Centre, Maastricht, The Netherlands \\ ${ }^{3}$ Department of Sociology \& Department of Human Geography, University Utrecht, Utrecht, The \\ Netherlands
}

\begin{abstract}
Background: Community participation has been defined as performing daytime activities by people while interacting with others. Previous studies on community participation among people with intellectual disability (ID) have mainly focused on the domestic life aspect. This study investigates the variation in community participation in the domains work, social contacts and leisure activities among people with ID in the Netherlands. A number of categories of people with ID were distinguished by: (1) gender; (2) age; (3) type of education; (4) severity of ID; and (5) accommodation type.

Methods: Data were gathered on 653 people with mild or moderate ID, of whom 513 by oral interviews and 140 by structured questionnaires filled in by representatives of those who could not be interviewed. Pearson chi-square tests were used to test differences between categories of people with ID in the distributions of the participation variables. Additional logistic regression analyses were conducted to correct for differences between the categories in other variables.

Results: Most people with mild or moderate ID in the Netherlands have work or other daytime activities, have social contacts and have leisure activities. However, people aged 50 years and over and people with moderate ID participate less in these domains than those under 50 years and people with mild ID. Moreover, people with ID hardly participate in activities with people without ID.

Conclusion: High participation among people with a mild or moderate ID within the domains of work, social contact and leisure activities does not necessarily indicate a high level of interaction with the community, because the majority hardly interact with people without ID. Furthermore, older people with ID and people with a more severe level of ID seem to be more at risk for social exclusion.
\end{abstract}

\section{INTRODUCTION}

In the past 30 years, many countries have implemented policy changes aimed at fostering community participation of people with intellectual disability (ID). Community participation in general is defined as performing daytime activities by people while interacting with others in: (1) domestic life; (2) interpersonal life (formal and informal social contacts); (3) major life activities (education and employment); and (4) community, civic and social life (hobbies, leisure activities and culture) (WHO 2001; van der Mei et al. 2006; Dalemans et al. 2008). So far, previous studies on community participation of people with ID have 
Dusseljee, J.C.E., Rijken, P.M., Cardol, M., Groenewegen, P.P., Curfs, L.M.G. Participation in daytime activities among people with mild or moderate intellectual disability. Journal of Intellectual Disability Research: 2011, 55(1), 4-18

mainly focused on the domestic life aspect. It was found that people with ID living in non-campus settings participate more in work or other daytime activities, social contacts and leisure activities than those living in campus settings (Verdonschot et al. 2009a). However, information on interpersonal life, major life activities and community, civic and social life of people with ID is scarce. Therefore, the aim of this study was to describe the current situation on community participation in the domains work or other daytime activities, social contacts and leisure activities by using a nationally representative panel of people with mild or moderate ID in the Netherlands. Thus, nationwide representative figures could be provided.

Recent studies show that people with ID participate less in the general community compared with people without ID (Myles et al. 2000; Verdonschot et al. 2009a). From a human rights point of view, it is undesirable that people with ID have lower levels of community participation. The right of disabled people to fully participate in the general community is covered in the United Nations convention on rights of persons with disabilities (UN 2006) and also in the Netherlands Equal Treatment Act for people with disabilities and chronic illness (WGBH/CZ). Accordingly, people with ID should have the opportunity to fully participate in the general community. Nevertheless, some evidence exists that people with ID have less community participation in interpersonal, major and social life activities compared with people without ID. However, the overview of people with ID in the Netherlands is incomplete.

A systematic review illustrated that people with ID are less often employed compared with people without ID: people with ID were 3 to 4 times less often employed (Verdonschot et al. 2009a). In addition, people with ID seem to engage less often in leisure activities and have less social contacts with family, friends and neighbours (Duvdevany \& Arar 2004). Furthermore, with respect to community participation, it is not only the level of participation that is important, but also whether people with ID interact with people without ID in the general community. In other words, community participation of people with ID should not only refer to activities in interaction with other people with ID, but also with people in the community who do not have ID. Therefore, this study not only looks at the extent of participation in daytime activities, but also includes the interaction with people without ID during these activities.

With respect to community participation in the general population, research shows that there are differences especially with regard to gender, age and type of education. There is a gender gap in employment, though this partly depends on education level. Employment rates increase with educational attainment, particularly for women. Gender employment gaps are smaller among the higher educated in the general population (OECD 2009). With regard to age, in the Netherlands, people aged 55 years and over, participate less in employment compared with other countries like Sweden and the UK (SCP 2002). However, there is diversity in the labour market situation of older people both within countries and across countries (OECD 2009). Regarding social contacts among the general population in the Netherlands, people have less social contacts, when they have a low educational level, do not have work and have a lower level of self-rated health (CBS 2000).

From this, we conclude that community participation in the general population is related to gender, age and type of education. The focus of this study is on people with ID and investigates whether there are also differences related to gender, age and the type of education within this population regarding their community participation. In addition, not only gender, age and the type of education may be relevant, some studies suggest that the severity of ID and the accommodation type might also have an effect on community participation in people with ID (Ager et al. 2001; McConkey et al. 2007; Cramm et al. 2009; Verdonschot et al. 2009b), although studies that give a complete overview on all these characteristics in relation to community participation are missing.

\section{Gender}

Information on community participation of people with ID is often gender-blind and separate data analyses for men and women are scarce (Thompson et al. 2002). In addition, women were found to be employed mainly in work specifically for people with ID and earn lower salaries compared with men with ID (Julius et al. 2003). However, on social contacts no differences between men and women with ID were found and with regard to leisure activities, one study even suggested higher participation for women (UmbCarlsson \& Sonnander 2006). Based on this limited evidence, we expected that men with ID more frequently than women with ID have work and more women with ID may have leisure activities compared with men with ID. 
Dusseljee, J.C.E., Rijken, P.M., Cardol, M., Groenewegen, P.P., Curfs, L.M.G. Participation in daytime activities among people with mild or moderate intellectual disability. Journal of Intellectual Disability Research: 2011, 55(1), 4-18

\section{Age}

There are hardly any studies that give information on daytime activities in younger vs. older people with ID (Ashman \& Suttie 1996; Taanila et al. 2005). One study showed that older people with ID ( $\geq 50$ years of age) have a smaller social network compared with younger people with ID (Ashman \& Suttie 1996). Moreover, older people with ID have less leisure activities compared with younger adults with ID (Taanila et al. 2005). A systematic review showed that younger disabled people were more often employed than older disabled people (Achterberg et al. 2009). Based on these findings, we expected that older people with ID not only participate less in work, but also in social contacts and in leisure activities compared with younger (adult) people with ID.

\section{Education}

A systematic review showed that type of education of disabled people was related to having work: a higher level of education reached by young people was positively associated with a higher chance of having work. In addition, primary education or less was associated with a lower chance of having work for people with disabilities (Achterberg et al. 2009). Given this result, a higher type of education might have a positive effect on having work in people with ID.

\section{Severity of ID}

There are several studies that relate the severity of the ID to daytime activities (Mank et al. 1998; LiTsang et al. 2005). One study researched 'having work' in people with ID in relation to the severity of ID: people with moderate ID less often work compared with people with mild ID (Mank et al. 1998). Another study confirmed that people with moderate ID have a lower type of education compared with people with mild ID (Li-Tsang et al. 2005). Therefore, it can be expected that less people with moderate ID have work, compared with people with mild ID.

\section{Accommodation type}

A number of studies examined the importance of accommodation type in relation to participation in people with ID (Duvdevany \& Arar 2004; McConkey et al. 2007; Kozma et al. 2009; Verdonschot et al. $2009 b$ ). A systematic review showed that people with ID who lived in a non-campus setting had a higher level of community participation compared with people with ID who lived in a campus setting (Kozma et al. 2009). Another study showed that the accommodation type had a significant influence on social contacts in people with ID. Participants who lived in campus settings, less often had social contacts with friends, compared with participants living in non-campus settings, such as foster homes and small group homes (Duvdevany \& Arar 2004). In contrast to these results, people with ID who live in campus settings have more social contact with family (McConkey et al. 2007). Nevertheless, people with ID living in noncampus settings are expected to have more opportunities to have social contact with people without ID (non-relatives), because they are more directly involved in the community.

This review of the literature shows that there are no studies that give a complete overview of the variation in community participation for people with ID in relation to: (1) gender; (2) age; (3) type of education; (4) severity of ID; and (5) accommodation type. Additionally, being involved in activities does not lead automatically to interaction with people without ID. Therefore, not only the daytime activities of people with ID need to be described, but also whether these activities are performed with people without ID.

Specifically, this study aims to answer the following research questions:

1 To what extent do people with mild or moderate ID participate in work, social contacts and leisure activities? And how much of this is in interaction with people without ID? and

2 To what extent does participation of people with ID vary by gender, age, type of education, severity of ID and accommodation type?

\section{METHOD}

\section{Procedure and participants}

This study is part of a nationwide research programme on community participation of people with ID in the Netherlands, called 'Panel Living Together' (PLT). PLT is a nationally representative panel of people with mild or moderate ID in the Netherlands and started in 2006 (Cardol et al. 2006). PLT is funded by the Netherlands ministry of Health, Welfare and Sports and the Netherlands ministry of Social Affairs and 
Dusseljee, J.C.E., Rijken, P.M., Cardol, M., Groenewegen, P.P., Curfs, L.M.G. Participation in daytime activities among people with mild or moderate intellectual disability. Journal of Intellectual Disability Research: 2011, 55(1), 4-18

Employment. Participants for PLT were recruited by general practitioners (random sample; $n=68$ ) and providers of care for people with ID $(n=52)$ in the Netherlands. General practitioners and care providers were asked to select potential panel members from their patients' or clients' files according to certain selection criteria. This inclusion criterion was: a diagnosis of a mild or moderate ID as defined by the American Association on Mental Retardation (AAMR) (Luckasson \& Reeve 2001).1 Exclusion criteria were: aged younger than 15 years, life expectancy of less than 6 months, and unfamiliarity with the Dutch language. Patients or clients who met the selection criteria were informed about the research by means of oral, written and digital information (compact disc) and were asked to participate. When patients or clients were considered unable to give informed consent, a legal representative was approached and asked for permission. Persons with ID could participate in PLT in three ways: (1) personal participation; (2) participation via a representative, a close relative or carer; and (3) participation by both the person with ID and his/her representative. In 2006, the total panel consisted of 927 panel members (513 people with ID and 414 representatives of people with ID) and contained information of 653 unique people with a mild or moderate ID, ranging in age from 15 to 88 years. These 653 people were living in $102(22 \%)$ of the total of 458 municipalities in the Netherlands and were spread all over the country (see Appendix 1). PLT is registered with the Dutch Data Protection Authority, and the data were collected according to the privacy protection guidelines of the Authority. More details of the study design of PLT have been described elsewhere (Cardol et al. 2006; Dusseljee et al. unpublished data).

\section{Data collection and measuring instruments}

Data for this study were collected in Autumn 2006 by means of oral interviews with panel members with ID $(n=513)$ or structured questionnaires filled in by representatives in case the participants with ID could not be interviewed themselves $(\mathrm{n}=140)$. In addition to these self-report data, several data were provided by the general practitioners or other care providers, such as specialised physicians for people with ID, psychologists, educators or social workers. These data were:

- Gender: male or female;

- Age: in years, for the purpose of this study categorised into four categories (15-34, 35-49, 50-64 and 65 years and over);

- Severity of the ID: mild or moderate;

- Accommodation type: campus setting (on the campus area or close to the campus area but also protected) and non-campus setting [supported living in group homes, independently (alone, with partner/children) or with family carers];

- Other physical and mental health problems besides ID: epilepsy, loss of locomotor activity, psychiatric problems and behavioural problems; and

- Type of education: which school type the participants had attended; for the purpose of this study categorised into four types: (1) general primary school; (2) special primary school; (3) general secondary school; and (4) special secondary school.

Data on participation in daytime activities were provided by the panel members (persons with ID or representatives) themselves. For this purpose, we developed an oral interview based on methods for interviewing people with ID as described by Flynn (1986) and Abbott \& McConkey (2006). The participation domains we distinguished were derived from the International Classification of Functioning, Disability and Health (WHO 2001) and covered activities and participation in the domains learning and applying knowledge, mobility, interpersonal interactions, domestic life, major life and community, social and civic life (Cardol et al. 2006). For the purpose of this study, we focused on participation in daytime activities and distinguished three types of participation: (1) participation in work or other daytime activities; (2) participation by means of social contacts; and (3) participation in leisure activities.

Participation in work or other daytime activities was assessed by three items: (1) having work or other daytime activities $(0=$ no, $1=$ yes $)$; (2) having paid work $(0=$ no, $1=$ yes $)$; and (3) having work or daytime activities not specifically for people with ID $(0=$ no, $1=$ yes $)$;

Participation by means of social contacts was assessed by five items: (1) having social contact with family $(0=$ no, $1=$ yes $) ;(2)$ having social contact with friends $(0=$ no, $1=$ yes $) ;(3)$ having social contact with friends without an ID ( $0=$ no, $1=$ yes $)$; (4) having social contact with neighbours ( $0=$ no, $1=$ yes $)$; and (5) having social contact with neighbours without an ID $(0=$ no, $1=$ yes $)$; and 
Dusseljee, J.C.E., Rijken, P.M., Cardol, M., Groenewegen, P.P., Curfs, L.M.G. Participation in daytime activities among people with mild or moderate intellectual disability. Journal of Intellectual Disability Research: 2011, 55(1), 4-18

Participation in leisure activities was assessed by two items: (1) whether the person with ID sometimes visited a restaurant, café, cinema or theatre $(0=$ no, $1=$ yes $)$; and ( 2$)$ whether he/she was engaged in leisure activities not specifically for people with ID $(0=$ no, $1=$ yes $)$.

\section{Data analysis}

The data were analysed using stata, version 10. First, preliminary data analyses were conducted to compare data provided by people with ID themselves (by means of oral interviews) with the data provided by representatives of the same people with ID (by means of structured questionnaires). Because we did not have data from both sources for every case, these analyses were done for a subsample $(n=274)$. The purpose of these analyses was to see if there were differences between the answers from both sources on the same questions regarding participation and if so, how large these differences were. Data on work or other daytime activities, social contacts and leisure activities were comparable for the most part; there were only small $(<5 \%)$ inconsistencies between both data sources. Therefore, further data analyses were done on the results of the interviews and proxy reports together and considered as one data source.

In order to answer the research questions, descriptive statistics were used. In order to compare the percentages for participation of different subgroups, Pearson chi-square tests were used to detect differences in the distributions of the participation variables between: (1) men and women; (2) people in four different age categories; (3) people with four different types of education; (4) people with mild vs. moderate ID; and (5) people who lived in a non-campus setting vs. a campus setting. On certain variables, data were missing for a small number of PLT panel members. The percentages and confidence intervals reported in the tables are calculated on the available data which are sometimes less than the total number of participants included in this study. The level of significance was set at $\mathrm{P}<0.05$. For each participation domain, results are presented in a separate table.

Additional logistic regression analyses were done to compute corrected percentages for each subgroup in this study, while controlling for the other variables. Percentages were corrected for gender [male (reference category) and female], severity of ID [mild (reference category) and moderate], type of education [general primary school (reference category), special secondary school, general secondary school and special secondary school], accommodation type [non-campus setting (reference category) and campus setting] and age (continuous variable). These corrected percentages for each participation domain were quite similar to the uncorrected percentages and therefore only the uncorrected percentages are shown in the Tables.

\section{RESULTS}

\section{Characteristics of the total study sample}

Of the 653 participants in this study, 55\% were males and $45 \%$ were females. More than one-third were people aged 50 years and over. The mean age of the total study sample was 43 years, ranging from 15 to 88 years. With respect to the type of education, about $9 \%$ had attended a general primary school and approximately $54 \%$ a special primary school. Around $7 \%$ attended or had attended a general secondary school and around $20 \%$ a special secondary school. There were $294(45 \%)$ participants diagnosed with mild ID, $278(43 \%)$ with moderate ID, and of 81 (12\%) participants the severity of their ID was unknown. Most participants lived in non-campus settings $(80 \%)$. A number of participants had additional health problems, such as epilepsy (8\%), loss of locomotor activity (16\%), psychiatric $(9 \%)$ and behavioural problems (17\%). The demographic and health characteristics of all participants in this study are presented in Table 1. In comparing the background characteristics of the interviewed participants to the proxy data of the panel members who could not be interviewed, some differences are visible. People who could be interviewed themselves more often had attended a secondary school, more had mild ID, they lived more often in a noncampus setting and had less health problems than those who could not be interviewed themselves.

\section{[TABLE 1]}

\section{Community participation of the total study sample}

Table 2 shows participation in the domains work, social contacts and leisure activities by the total study sample. More than $90 \%$ had work or other daytime activities. However, approximately $47 \%$ had paid work and only $14 \%$ had work or other daytime activities not specifically for people with ID. With respect to 
Dusseljee, J.C.E., Rijken, P.M., Cardol, M., Groenewegen, P.P., Curfs, L.M.G. Participation in daytime activities among people with mild or moderate intellectual disability. Journal of Intellectual Disability Research: 2011, 55(1), 4-18

social contacts, most participants (69\%) in this study had social contacts with family, $35 \%$ had contacts with friends and $12 \%$ had contacts with their neighbours. Furthermore, only $12 \%$ had social contacts with friends without ID and around 7\% had contacts with neighbours without ID. With regard to leisure activities, $71 \%$ visited a restaurant/café/cinema or theatre now and then and $36 \%$ engaged in leisure activities not specifically organised for people with ID.

\section{[TABLE 2]}

\section{Gender}

Table 3 provides the percentages for community participation for men and women separately. With respect to social contacts, the results show that men more often had contact with friends without ID compared with women. Men also more often visited a restaurant/café/cinema or theatre, when compared with women.

\section{[TABLE 3]}

\section{Age}

Table 4 summarises the participation percentages by age group. The results show that among the three youngest age groups, most had work or other daytime activities. However, a smaller amount of the oldest age group ( $\geq 65$ years of age) had work or other daytime activities. In addition, fewer people had work or other activities not specifically organised for people with ID, compared with 'having work or other not specified daytime activities'. With respect to social contacts, older adults with ID (aged 50 years and over) had less social contacts with family and friends and had less leisure activities compared with younger people with ID.

\section{[TABLE 4]}

\section{Type of education}

The general primary school group less often had work or other daytime activities, paid work and work or other daytime activities not special for people with ID, compared with the other education groups (Table 5). With respect to social contact, fewer people in the general primary school group had contact with family and friends, and a small part visited a restaurant/café/cinema or theatre compared with the other education groups.

\section{[TABLE 5]}

\section{Severity of ID}

Table 6 illustrates the community participation of the participants with mild ID and moderate ID separately. As expected, fewer people with moderate ID had paid work compared with people with mild ID. In addition, fewer people with moderate ID had work or other daytime activities not specifically organised for people with ID, and they had social contact with friends, including those without ID than people with mild ID.

\section{[TABLE 6]}

\section{Accommodation type}

People who lived in campus settings had less paid work compared with people who lived in non-campus settings (Table 7). In addition, people who lived in campus settings had more social contact with neighbours compared with people that lived in non-campus settings. However, those living in non-campus settings had more social contact with neighbours without ID. 
Dusseljee, J.C.E., Rijken, P.M., Cardol, M., Groenewegen, P.P., Curfs, L.M.G. Participation in daytime activities among people with mild or moderate intellectual disability. Journal of Intellectual Disability Research: 2011, 55(1), 4-18

\section{[TABLE 7]}

\section{DISCUSSION}

This study aimed to describe the participation in the domains work or other daytime activities, social contacts and leisure activities among people with a mild or moderate ID in the Netherlands. Overall, this study demonstrates that most people with ID have work or other daytime activities, have social contacts and engage in leisure activities. However, the majority of people with ID hardly interact with people without ID. In particularly, older adults and people with a moderate ID have a lower level of community participation.

\section{Comparison with other studies}

In the present study, the participation domains are not only viewed upon from a general perspective. In more detail, subgroups were used to study the potential influence on community participation in people with ID. These subgroups were distinguished by gender, age, type of education, severity of ID and accommodation type.

With respect to gender, the present study found that differences exist between men and women with ID. Men were more socially active with friends without ID and had more leisure activities. These differences were not specifically looked at in other studies, although it had been suggested that men had a higher chance of having work compared with women (Ager et al. 2001; Julius et al. 2003). This outcome however was not supported by the results of the present study.

With regard to age, older people (aged 50 years and over) were shown to have less social contacts with family and friends compared with younger people. In addition, older adults have fewer daytime activities that were not specifically organised for people with ID. These results were similar with those found in other studies (Ashman \& Suttie 1996; Ager et al. 2001). In the present study, older adults had a lower percentage on leisure activities not specially organised for people with ID compared with younger adults. However, this percentage was not that low as on the other activities not specially organised for people with ID among the older adults. A possible explanation could be that older adults with ID had activities in day activity centres for elderly people and not particularly for people with ID. In reflection of these results, getting older will lead to a decrease in social contacts with family and friends. Therefore, age may play a crucial role in community participation in people with ID: the higher the age, the lower the participation level. Further research should give more insight into the effect of age in relation to community participation.

With regard to education, it was found that people with ID who attended or had attended a (general or special) secondary school more often had paid work and social contact with friends than people with ID who had attended only primary school. A review showed that disabled people who reached a higher level of education had a higher chance of having work (Achterberg et al. 2009). These results show that a higher level of education in people with ID results in a higher level of community participation in people with ID as well. In this study we also looked at differences between people with ID attending schools for general or special education. However, the type of education (general vs. special) appeared to be related to age: older adults had mostly attended a general primary school and younger adults more often had attended a special school. This is because in earlier days special education for people with learning disabilities did not exist. In this study there were no clear differences in community participation between people with ID who had attended a general school compared with people who had attended a special school. Because of the interrelationship between education type and age, we cannot conclude from these findings that the type of education does not have an impact on the chances of community participation for people with ID. Further research in this area is needed.

In the present study, large differences were found in the percentages for the community participation domains between people with mild and moderate ID. The findings show that people with moderate ID have a lower level of participation in work or other daytime activities, in work or other activities not specifically organised for people with ID, in social contacts with friends and friends without ID. Other studies found similar results for people with moderate vs. mild ID regarding community participation (Mank et al. 1998; Li-Tsang et al. 2005). The results of the present study imply that the severity of ID play an important role on the community participation in people with ID.

With respect to accommodation type, people that lived in campus settings had a much lower percentage on 'having paid work' and social contacts with neighbours without ID compared with people that lived in non- 
Dusseljee, J.C.E., Rijken, P.M., Cardol, M., Groenewegen, P.P., Curfs, L.M.G. Participation in daytime activities among people with mild or moderate intellectual disability. Journal of Intellectual Disability Research: 2011, 55(1), 4-18

campus settings. Other studies found a low percentage for social contact with friends for people that lived in campus settings (Duvdevany \& Arar 2004; Verdonschot et al. 2009b). In sum, accommodation type of people with ID might influence community participation, but this can be explained by the fact that more people with moderate ID lived in a campus setting compared with people with mild ID.

\section{Strengths and limitations}

This study has several strengths that make its results robust. First, this is the first study that is based on information gathered in a nationwide representative panel of people with ID, the Netherlands PLT. PLT is, as far as we know, the only national panel in Europe or even worldwide, which consists of a large representative sample of people with ID and their representatives and it is therefore a unique source of information provided by people with ID themselves. The purpose of PLT is that people with ID have the possibility to give their own opinion and to speak for themselves about their participation into the community (Cardol et al. 2006). We verified that PLT is in fact a representative panel for people with mild or moderate ID in the Netherlands by comparing the included sample with those of other research published on people with ID in the Netherlands (de Klerk 2002, 2004; Van Schrojenstein Lantman-de Valk et al. 2002). Only small differences in frequencies were found which could be attributed to differences in the selection criteria used in the different studies. Second, to prevent selection bias, the data of the total study sample not only consisted of information on the people with ID who could be interviewed, but also of information from representatives of people with ID who could not be interviewed themselves. Consequently, people with low communication skills, who would normally be excluded, are also represented in the panel. This provides a more valid percentage of community participation of people with mild or moderate ID. However, because the data were collected by applying different methods (interviews vs. questionnaires and self-report vs. proxy-report) not all variables could be matched appropriately.

Because of this limitation, a selection had to be made in the variables that matched and the data that were available for this study. Sport activity, as an important indicator of leisure activities, was not inquired in the interviews of people with ID, though it was assessed in the questionnaires of the representatives of people with ID. Therefore, this indicator could not be used in this study, which may have limited our insight into the percentages of leisure activity. Another limitation of this study can be found in the information provided by the representatives of people with low communication skills. Only small differences were found in the way the representatives interpreted the 'true situation' of community participation of the people with ID in the different domains, compared with the information based on the self-reported data of the people with ID. If people with more severe ID would have been able to describe their own community participation, they might have described it differently. In addition, people with ID who participated in this study could have given social desirable answers during the interview, which can result in a social desirability response bias (Nederhof 1981). Nevertheless, this seems unlikely because this study only looked at actual participation indicators and not at subjective experiences such as 'satisfaction with participation', and the data were also gathered by questionnaires filled in by representatives of the people with ID and compared with the data on the interviews.

\section{Implications for services and for further research}

This study brings forth descriptive insights into the participation of people with ID in the general community. It shows that people with ID participate less with people without ID and as a consequence interact less with the general community. On first sight it would seem that current policy for people with ID should focus more on increasing the participation of people with ID with people without ID. However, before input can be given to actively improve social inclusion of people with ID, the facilitating and inhibiting factors, both should be explored in more detail. It seems that the variety of factors are complex in community participation among people with ID, such as age, the severity of ID, other disabilities besides ID such as communication disabilities, the accessibility of workplaces and leisure activities, having support of family and a need of personal support. Therefore, difficulties of providing for an adequate and wellprepared workforce to support community participation among people with ID are complex and multifaceted. Nevertheless, it is clear that the need exists for community-based support services to develop effective approaches for community participation among people with ID.

Concerning work and leisure activities certain barriers exist that might impede the participation of people with ID with people without ID. Employment of people with ID in the general community is considered to stimulate community participation and inclusion with people without disabilities (Fillary \& Pernice 2006). 
Dusseljee, J.C.E., Rijken, P.M., Cardol, M., Groenewegen, P.P., Curfs, L.M.G. Participation in daytime activities among people with mild or moderate intellectual disability. Journal of Intellectual Disability Research: 2011, 55(1), 4-18

However, accessibility of workplaces could be a barrier to have work among people with ID. And when they do have work, after work- socialising might be difficult because of the mostly part-time working days of people with ID. With respect to leisure activities, barriers to participate in the community could be underdeveloped leisure skills, lack of support to participate in leisure activity opportunities, lack in social network, problems in health status, other disabilities next to ID, certain changes in social network and changes in health status because of ageing. In addition, lack of transport, and not having someone to support in the activity or even not having enough money to engage in community based leisure activity could also be barriers to participate (Buttimer \& Tierney 2005).

Leisure activities and having work in the community are important issues for community participation. Not having work and leisure activities in the community can result in not having or having few social contacts with people without ID. To stimulate these participation activities, social support and other resources may be of utmost importance. Further research into the availability of the resources among people with ID such as friendships, social support, the role of parents and family, having money, transport and the role of service providers are considered to provide the insights needed to improve the participation of people with ID. Especially the complexity of the variety of factors such as ageing, support and resources among people with ID are important issues in further research.

\section{CONCLUSION}

The results of this study show that most participants had work or other daytime activities. However, high participation among people with a mild or moderate ID within the domains of work, social contact and leisure activities does not necessarily indicate a high level of interaction with the community, because the majority hardly interact with people without ID. Furthermore, older people with ID and people with a more severe level of ID seem to be more at risk for social exclusion.

\section{ACKNOWLEDGEMENTS}

We would like to express our thanks to all PLT panel members: the people with ID and their representatives, the general practitioners and settings for people with ID. This research was funded by the Netherlands Ministry of Health, Welfare and Sports, the Dutch ministry of Social Affairs and Employment and the Netherlands Organization for Health Research and Development (ZonMw).

\section{REFERENCES}

Abbott S. \& McConkey R. (2006) The barriers to social inclusion as perceived by people with ID. Journal of Intellectual Disabilities 10, 275-87.

Achterberg T. J., Wind H., de Boer A. G. \& Frings-Dresen M. H. (2009) Factors that promote or hinder young disabled people in work participation: a systematic review. Journal of Occupational Rehabilitation 19, 129-41.

Ager A., Myers F., Kerr P., Myles S. \& Green A. (2001) Moving home: social integration for adults with intellectual disabilities resettling into community provision. Journal of Intellectual Disability Research 14, 392-400.

Ashman A. F. \& Suttie J. N. (1996) The social and community involvement of older Australians with intellectual disabilities. Journal of Intellectual Disability Research 40 ( Pt 2 ), 120-9.

Buttimer J. \& Tierney E. (2005) Patterns of leisure participation among adolescents with a mild intellectual disability. Journal of Intellectual Disabilities 9, 25-42.

Cardol M., Speet M. \& Rijken M. (2006) Anders of toch niet? Deelname aan de samenleving van mensen met een lichte of matige verstandelijke beperking. NIVEL, Utrecht.

CBS (2000) Nederland en Europa: Eén Europa van de arbeid? CBS, Den Haag.

Cramm J. M., Finkenflugel H., Kuijsten R. \& van Exel N. J. (2009) How employment support and social integration programmes are viewed by the intellectually disabled. Journal of Intellectual Disability Research 53, 512-20.

Dalemans R., de Witte L. P., Lemmens J., van den Heuvel W. J. \& Wade D. T. (2008) Measures for rating social participation in people with aphasia: a systematic review. Clinical Rehabilitation 22, 542-55. 
Dusseljee, J.C.E., Rijken, P.M., Cardol, M., Groenewegen, P.P., Curfs, L.M.G. Participation in daytime activities among people with mild or moderate intellectual disability. Journal of Intellectual Disability Research: 2011, 55(1), 4-18

Duvdevany I. \& Arar E. (2004) Leisure activities, friendships, and quality of life of persons with intellectual disability: foster homes vs community residential settings. International Journal of Rehabilitation Research 27, 289-96.

Fillary R. \& Pernice R. (2006) Social inclusion in workplaces where people with intellectual disabilities are employed: implications for supported employment professionals. International Journal of Rehabilitation Research 29, 31-6.

Flynn M. C. (1986) Adult who are mentally handicapped as consumers: issues and guidelines for interviewing. Journal of Mental Deficiency Research 30, 368-77.

Julius E., Wolfson H. \& Yalon-Chamovitz S. (2003) Equally unequal: gender discrimination in the workplace among adults with mental retardation. Work 20, 205-13.

de Klerk M. M. Y. (2002) Verstandelijke handicap samengevat: Nationaal Kompas Volksgezondheid RIVM. RIVM, Bilthoven.

de Klerk M. M. Y. (2004) Hoe vaak komt een verstandelijke beperking voor?: Nationaal Kompas Volksgezondheid. RIVM, Bilthoven.

Kozma A., Mansell J. \& Beadle-Brown J. (2009) Outcomes in different residential settings for people with intellectual disability: a systematic review. American Journal on Intellectual and Developmental Disabilities 114, 193-222.

Li-Tsang C., Yeung S., Chan C. \& Hui-Chan C. (2005) Factors affecting people with intellectual disabilities in learning to use computer technology. International Journal of Rehabilitation Research 28, 127-33.

Luckasson R. \& Reeve A. (2001) Naming, defining, and classifying in mental retardation. Mental Retardation 39, 47-52.

McConkey R., Abbott S., Walsh P. N., Linehan C. \& Emerson E. (2007) Variations in the social inclusion of people with intellectual disabilities in supported living schemes and residential settings. Journal of Intellectual Disability Research 51, 207-17.

Mank D., Cioffi A. \& Yovanoff P. (1998) Employment outcomes for people with severe disabilities: opportunities for improvement. Mental Retardation 36, 205-16.

van der Mei S. F., Krol B., van Son W. J., de Jong P. E., Groothoff J. W. \& van den Heuvel W. J. (2006) Social participation and employment status after kidney transplantation: a systematic review. Quality of Life Research 15, 979-94.

Myles S., Ager A., Kerr P., Myers F. \& Walker J. (2000) Moving home: costs associated with different models of accommodation for adults with learning disabilities. Health and Social Care in the Community 8 , 406-16.

Nederhof A. J. (1981) Beter Onderzoek: bestrijding van foutenbronnen in sociaal-wetenschappelijk onderzoek. VUGA, 's-Gravenhage.

OECD (2009) Gender Differences in Employment Outcomes. OECD, Paris-France.

Schalock R. L., Borthwick-Duffy S. A., Bradley V. J., Buntinx W. H. E., Coulter D. L., Craig E. M. et al. (2010) Intellectual Disability: Definition, Classification, and System of Supports (Eleventh Edition). AAID, Washington DC.

SCP (2002) Rapportage gehandicapten: Maatschappelijke positie van mensen met lichamelijke beperkingen of verstandelijke handicaps. SCP, Den Haag.

Taanila A., Rantakallio P., Koiranen M., von Wendt L. \& Jarvelin M. R. (2005) How do persons with intellectual disability manage in the open labour markets? A follow-up of the Northern Finland 1966 Birth Cohort. Journal of Intellectual Disability Research 49, 218-27.

Thompson J. R., Hughes C., Schalock R. L., Silverman W., Tassé M. J., Bryant B. et al. (2002) Integrating supports in assessment and planning. Mental Retardation 40, 390-405.

Umb-Carlsson O. \& Sonnander K. (2006) Living conditions of adults with intellectual disabilities from a gender perspective. Journal of Intellectual Disability Research 50, 326-34.

UN (2006) Convention on the Rights of Persons with Disabilities. UN Headquarters, New York.

Van Schrojenstein Lantman-de Valk H. M. J., Van Heurn-Nijsten E. W. A. \& Wullink M. (2002) Prevalentieonderzoek mensen met een verstandelijke beperking in Nederland. Maastricht University, Maastricht.

Verdonschot M. M., de Witte L. P., Reichrath E., Buntinx W. H. \& Curfs L. M. (2009a) Community participation of people with an intellectual disability: a review of empirical findings. Journal of Intellectual Disability Research 53, 303-18.

Verdonschot M. M., de Witte L. P., Reichrath E., Buntinx W. H. \& Curfs L. M. (2009b) Impact of environmental factors on community participation of persons with an intellectual disability: a systematic review. Journal of Intellectual Disability Research 53, 54-64.

WHO (2001) World Health Organization (WHO) International Classification of Functioning, Disability and Health. WHO, Geneva. 
Dusseljee, J.C.E., Rijken, P.M., Cardol, M., Groenewegen, P.P., Curfs, L.M.G. Participation in daytime activities among people with mild or moderate intellectual disability. Journal of Intellectual Disability Research: 2011, 55(1), 4-18

\section{[TABLES]}

Table I Characteristics of the total study sample

\begin{tabular}{|c|c|c|c|c|c|c|c|}
\hline \multirow[b]{2}{*}{ Variable } & \multicolumn{2}{|c|}{ Total group } & \multicolumn{2}{|c|}{$\begin{array}{l}\text { Interviewees } \\
\text { with ID }\end{array}$} & \multicolumn{2}{|c|}{$\begin{array}{l}\text { People with ID } \\
\text { (according to } \\
\text { relatives) }\end{array}$} & \multirow[b]{2}{*}{$\chi^{2}$ (d.f.), $P$-value } \\
\hline & $n=653$ & $\%$ & $n=513$ & $\%$ & $n=140$ & $\%$ & \\
\hline Gender & & & & & & & $1.78(1), P=0.18$ \\
\hline Male & 359 & 55.0 & 289 & 56.3 & 70 & 50.0 & \\
\hline Female & 294 & 45.0 & 224 & 43.7 & 70 & 50.0 & \\
\hline Age (in years) & & & & & & & $5.16(3), P=0.16$ \\
\hline Mean age (SD) & 42.9 & $(15.1)$ & 43.3 & $(14.8)$ & 41.5 & $(16.3)$ & \\
\hline $15-34$ & 217 & 33.2 & 160 & 31.2 & 57 & 40.7 & \\
\hline $35-49$ & 211 & 32.3 & 174 & 33.9 & 37 & 26.4 & \\
\hline $50-64$ & 166 & 25.4 & 133 & 25.9 & 33 & 23.6 & \\
\hline$\geq 65$ & 59 & 9.0 & 46 & 9.0 & 13 & 9.3 & \\
\hline Type of education & & & & & & & $|0.9|(4), P=0.03$ \\
\hline \multicolumn{8}{|l|}{ Primary school } \\
\hline General & 56 & 8.6 & 43 & 8.4 & 13 & 9.3 & \\
\hline Special & 350 & 53.6 & 275 & 53.6 & 75 & 53.6 & \\
\hline \multicolumn{8}{|l|}{ Secondary school } \\
\hline General & 48 & 7.4 & 42 & 8.2 & 6 & 4.3 & \\
\hline Special & 129 & 19.8 & 107 & 20.9 & 22 & 15.7 & \\
\hline Unknown & 70 & 10.7 & 46 & 9.0 & 24 & I7.| & \\
\hline Severity of ID & & & & & & & 86.01 (2), $P<0.01$ \\
\hline Mild & 294 & 45.0 & 263 & 51.3 & 31 & 22.1 & \\
\hline Moderate & 278 & 42.6 & 171 & 33.3 & 107 & 76.4 & \\
\hline Unknown & 81 & 12.4 & 79 & 15.4 & 2 & 1.4 & \\
\hline Accommodation type & & & & & & & 42.27 (2), $P<0.01$ \\
\hline Campus settings & 112 & 17.2 & 63 & 12.3 & 49 & 35.0 & \\
\hline On campus setting & 90 & 13.8 & 51 & 10.0 & 39 & 27.9 & \\
\hline Close to campus area & 22 & 3.4 & 12 & 2.3 & 10 & 7.1 & \\
\hline Non-campus settings & 517 & 79.2 & 431 & 84.0 & 86 & 61.4 & \\
\hline Group homes & 309 & 47.4 & 239 & 46.6 & 70 & 50.0 & \\
\hline Independently & 157 & 24.0 & 154 & 30.0 & 3 & 2.1 & \\
\hline With family carers & 51 & 7.8 & 38 & 7.4 & 13 & 9.3 & \\
\hline Unknown & 24 & 3.6 & 19 & 3.7 & 5 & 3.6 & \\
\hline \multicolumn{8}{|l|}{ Other health problems } \\
\hline Epilepsy $(n=65 \mathrm{I})$ & $n=54$ & 8.3 & 33 & 6.4 & 21 & 15.2 & II.03 (I), $P<0.01$ \\
\hline Loss of mobility $(n=644)$ & $n=102$ & 15.8 & 54 & 10.5 & 48 & 36.6 & 53.39 (I), $P<0.01$ \\
\hline Psychiatric $(n=64 I)$ & $n=57$ & 8.9 & 29 & 5.7 & 28 & 20.9 & 33.27 (I), $P<0.01$ \\
\hline Behavioural $(n=650)$ & $n=109$ & 16.8 & 24 & 4.7 & 85 & 62.0 & 254.93 (I), $P<0.01$ \\
\hline
\end{tabular}

Bold denotes statistical significance $(P<0.05)$ determined by chi square analysis.

ID, intellectual disability. 
Dusseljee, J.C.E., Rijken, P.M., Cardol, M., Groenewegen, P.P., Curfs, L.M.G. Participation in daytime activities among people with mild or moderate intellectual disability. Journal of Intellectual Disability Research: 2011, 55(1), 4-18

Table 2 Participation of the total study sample in work or other daytime activities, social contacts and leisure activities

\begin{tabular}{llrrr}
\hline Variable & Indicator & $n$ & Yes & $\%(95 \% \mathrm{Cl})$ \\
\hline \multirow{2}{*}{ Employment status } & & 653 & 598 & $91.6(89.4-93.7)$ \\
& Having work or other daytime activities & 594 & 572 & $96.3(94.8-97.8)$ \\
& Having work or other daytime activities (<65 years) & 571 & 270 & $47.3(43.2-51.4)$ \\
& Having paid work (<65 years) & 653 & 91 & $13.9(11.3-16.6)$ \\
& Having work or other daytime activities not specially & & & \\
Social contact with & for people with ID & 640 & 439 & $68.6(65.0-72.2)$ \\
& Family & 625 & 221 & $35.4(31.6-39.1)$ \\
& Friends & 610 & 72 & $11.8(9.2-14.4)$ \\
& Friends without ID & 631 & 75 & $11.9(9.4-14.4)$ \\
& Neighbours & 607 & 40 & $6.6(4.6-8.6)$ \\
Leisure activities & Neighbours without ID & 638 & 450 & $70.5(67.0-74.1)$ \\
& Visit sometimes a restaurant/café/cinema/theatre & 577 & 206 & $35.7(31.8-39.6)$ \\
\hline
\end{tabular}

ID, intellectual disability.

Table 3 Percentages of community participation for men and women separately

\begin{tabular}{|c|c|c|c|c|}
\hline Variable & Indicator & $n$ & $\begin{array}{l}\text { Male }(n=359) \\
\%(95 \% \mathrm{Cl})\end{array}$ & $\begin{array}{l}\text { Female }(n=294) \\
\%(95 \% \mathrm{Cl})\end{array}$ \\
\hline \multirow[t]{4}{*}{ Employment status } & Having work or other daytime activities & 653 & $92.8(90.1-95.4)$ & 90.1 (86.7-93.6) \\
\hline & Having work or other daytime activities (<65 years) & 594 & $97.0(95.2-98.8)$ & $95.4(92.8-98.0)$ \\
\hline & Having paid work ( $<65$ years) & 571 & $48.1(42.6-53.6)$ & $46.2(40.0-52.4)$ \\
\hline & $\begin{array}{l}\text { Having work or other daytime activities not specially } \\
\text { for people with ID }\end{array}$ & 653 & $14.5(10.8-18.1)$ & $13.9(11.3-16.6)$ \\
\hline \multirow[t]{5}{*}{ Social contact with } & Family & 640 & $69.5(64.7-74.3)$ & $67.5(62.1-72.9)$ \\
\hline & Friends & 625 & $35.7(30.7-40.8)$ & $34.9(29.3-40.5)$ \\
\hline & Friends without ID & 610 & $14.3(10.6-18.1)$ & $8.6(5.2-11.9)$ \\
\hline & Neighbours & 631 & $12.8(9.3-16.3)$ & $10.8(7.1-14.4)$ \\
\hline & Neighbours without ID & 607 & $7.4(4.6-10.2)$ & $5.6(2.8-8.3)$ \\
\hline \multirow[t]{2}{*}{ Leisure activities } & Visit sometimes a restaurant/café/cinema/theatre & 638 & $74.4(69.8-78.9)$ & $65.9(60.3-71.4)$ \\
\hline & Leisure activities not specially for people with ID & 577 & $38.0(32.6-43.3)$ & $33.0(27.2-38.7)$ \\
\hline
\end{tabular}

Bold denotes statistical significance $(P<0.05)$ determined by chi square analysis. ID, intellectual disability. 
Dusseljee, J.C.E., Rijken, P.M., Cardol, M., Groenewegen, P.P., Curfs, L.M.G. Participation in daytime activities among people with mild or moderate intellectual disability. Journal of Intellectual Disability Research: 2011, 55(1), 4-18

Table 4 Percentages of community participation for age groups (in years) separately

\begin{tabular}{|c|c|c|c|c|c|c|}
\hline \multirow[b]{2}{*}{ Variable } & \multirow[b]{2}{*}{ Indicator } & \multirow[b]{2}{*}{$n$} & \multicolumn{4}{|c|}{ Age (in years) } \\
\hline & & & $\begin{array}{l}15-34(n=217) \\
\%(95 \% \mathrm{Cl})\end{array}$ & $\begin{array}{l}35-49(n=211) \\
\%(95 \% \mathrm{Cl})\end{array}$ & $\begin{array}{l}50-64(n=166) \\
\%(95 \% \mathrm{Cl})\end{array}$ & $\begin{array}{l}\geq 65(n=59) \\
\%(95 \% \mathrm{Cl})\end{array}$ \\
\hline \multirow[t]{4}{*}{$\begin{array}{l}\text { Employment } \\
\text { status }\end{array}$} & $\begin{array}{l}\text { Having work or other daytime } \\
\text { activities }\end{array}$ & 653 & $98.6(97.1-1.00)$ & 96.7 (94.3-99.I) & $92.8(88.8-96.7)$ & $44.1(31.3-56.9)$ \\
\hline & $\begin{array}{l}\text { Having work or other daytime } \\
\text { activities ( }<65 \text { years) }\end{array}$ & 594 & $98.6(97.1-1.00)$ & $96.7(94.3-99.1)$ & $92.8(88.8-96.7)$ & \\
\hline & Having paid work (<65 years) & 571 & $42.6(35.7-49.4)$ & $51.9(45.1-58.7)$ & $47.2(39.4-55.0)$ & \\
\hline & $\begin{array}{l}\text { Having work or other daytime } \\
\text { activities not specially for } \\
\text { people with ID }\end{array}$ & 653 & $20.3(14.9-25.7)$ & $13.3(9.7-17.9)$ & $10.2(5.6-14.9)$ & $3.4(0-8.1)$ \\
\hline \multirow{5}{*}{$\begin{array}{l}\text { Social } \\
\text { contact } \\
\text { with }\end{array}$} & Family & 640 & $78.9(73.4-84.4)$ & $71.8(65.6-77.9)$ & $58.8(51.1-66.4)$ & $46.6(33.6-59.8)$ \\
\hline & Friends & 625 & $50.5(43.7-57.3)$ & $29.2(22.9-35.5)$ & $27.9(20.8-34.9)$ & $22.8(11.8-33.8)$ \\
\hline & Friends without ID & 610 & $16.4(\mid 1.4-21.5)$ & $9.7(5.5-13.9)$ & $8.6(4.1-13.1)$ & $10.7(2.5-18.9)$ \\
\hline & Neighbours & 631 & 15.7 (I0.8-20.7) & $11.8(7.3-16.2)$ & $8.1(3.9-12.4)$ & $8.8(1.3-16.2)$ \\
\hline & Neighbours without ID & 607 & $8.4(4.5-12.2)$ & $8.6(4.7-12.5)$ & $4.0(0.8-7.1)$ & \\
\hline \multirow[t]{2}{*}{$\begin{array}{l}\text { Leisure } \\
\text { activities }\end{array}$} & $\begin{array}{l}\text { Visit sometimes a restaurant/ } \\
\text { café/cinema/theatre }\end{array}$ & 638 & $81.2(76.0-86.5)$ & $75.5(69.6-81.4)$ & $58.8(51.1-66.4)$ & $45.6(32.5-58.7)$ \\
\hline & $\begin{array}{l}\text { Leisure activities not specially } \\
\text { for people with ID }\end{array}$ & 577 & $45.5(38.3-52.7)$ & $36.5(29.6-43.3)$ & $26.0(18.8-33.2)$ & $25.0(12.8-37.2)$ \\
\hline
\end{tabular}

Bold denotes statistical significance $(P<0.05)$ determined by chi square analysis.

ID, intellectual disability. 
Dusseljee, J.C.E., Rijken, P.M., Cardol, M., Groenewegen, P.P., Curfs, L.M.G. Participation in daytime activities among people with mild or moderate intellectual disability. Journal of Intellectual Disability Research: 2011, 55(1), 4-18

Table 5 Percentages of community participation for different types of education separately

\begin{tabular}{|c|c|c|c|c|c|c|}
\hline \multirow[b]{2}{*}{ Variable } & \multirow[b]{2}{*}{ Indicator } & \multirow[b]{2}{*}{$n$} & \multicolumn{2}{|c|}{ Primary school } & \multicolumn{2}{|c|}{ Secondary school } \\
\hline & & & $\begin{array}{l}\text { General } \\
(n=56) \\
\%(95 \% \mathrm{Cl})\end{array}$ & $\begin{array}{l}\text { Special } \\
(n=350) \\
\%(95 \% \mathrm{Cl})\end{array}$ & $\begin{array}{l}\text { General } \\
(n=48) \\
\%(95 \% \mathrm{Cl})\end{array}$ & $\begin{array}{l}\text { Special } \\
(n=129) \\
\%(95 \% \mathrm{Cl})\end{array}$ \\
\hline \multirow[t]{4}{*}{$\begin{array}{l}\text { Employment } \\
\text { status }\end{array}$} & $\begin{array}{l}\text { Having work or other } \\
\text { daytime activities }\end{array}$ & 583 & $71.4(59.5-83.3)$ & $94.6(92.2-97.0)$ & 91.7 (83.8-99.6) & $94.6(90.6-98.5)$ \\
\hline & $\begin{array}{l}\text { Having work or other } \\
\text { daytime activities } \\
\text { (<65 years) }\end{array}$ & 541 & $94.3(86.2-1.02)$ & 97.6 (95.9-99.3) & 91.3 (82.8-99.8) & $94.5(90.5-98.5)$ \\
\hline & $\begin{array}{l}\text { Having paid work } \\
\text { ( }<65 \text { years })\end{array}$ & 521 & $33.3(16.4-50.3)$ & $45.0(39.6-50.5)$ & $62.2(47.5-77.0)$ & $56.2(47.2-65.2)$ \\
\hline & $\begin{array}{l}\text { Having work or other } \\
\text { daytime activities not } \\
\text { specially for people } \\
\text { with ID }\end{array}$ & 583 & $7.1(0.2-14.1)$ & II.7 (8.3-15.I) & $14.6(4.2-24.9)$ & $24.8(17.3-32.4)$ \\
\hline \multirow{5}{*}{$\begin{array}{l}\text { Social } \\
\text { contact } \\
\text { with }\end{array}$} & Family & 572 & $43.4(29.9-56.9)$ & $71.9(67.2-76.7)$ & $68.8(55.5-82.0)$ & $74.4(66.8-82.0)$ \\
\hline & Friends & 562 & $13.5(4.1-22.8)$ & $35.5(30.4-40.7)$ & $50.0(35.7-64.3)$ & $44.9(36.2-53.6)$ \\
\hline & Friends without ID & 552 & $10.0(1.6-18.4)$ & II.6 (8.I-|5.0) & $31.3(18.0-44.5)$ & $9.6(4.4-14.8)$ \\
\hline & Neighbours & 565 & $9.4(1.5-17.4)$ & $13.3(9.7-16.9)$ & $10.4(1.7-19.2)$ & $10.3(5.0-15.7)$ \\
\hline & Neighbours without ID & 547 & $2.0(0-5.8)$ & $8.0(5.0-10.9)$ & $4.3(0-10.1)$ & $7.4(2.7-12.0)$ \\
\hline \multirow[t]{2}{*}{$\begin{array}{l}\text { Leisure } \\
\text { activities }\end{array}$} & $\begin{array}{l}\text { Visit sometimes a restaurant/ } \\
\text { café/cinema/theatre }\end{array}$ & 634 & $49.0(35.1-62.9)$ & $75.3(70.7-79.9)$ & $64.6(50.9-78.3)$ & $68.2(60.1-72.3)$ \\
\hline & $\begin{array}{l}\text { Leisure activities not } \\
\text { specially for people } \\
\text { with ID }\end{array}$ & 573 & $26.0(13.4-38.6)$ & $38.4(32.9-43.8)$ & $31.9(18.1-45.7)$ & $33.9(25.2-42.6)$ \\
\hline
\end{tabular}

Bold denotes statistical significance $(P<0.05)$ determined by chi square analysis.

ID, intellectual disability.

Table 6 Percentages of community participation for people with a mild and moderate ID separately

\begin{tabular}{|c|c|c|c|c|}
\hline Variable & Indicator & $n$ & $\begin{array}{l}\text { Mild ID } \\
(n=294) \\
\%(95 \% \mathrm{Cl})\end{array}$ & $\begin{array}{l}\text { Moderate ID } \\
(n=278) \\
\%(95 \% \mathrm{Cl})\end{array}$ \\
\hline \multirow[t]{4}{*}{ Employment status } & Having work or other daytime activities & 572 & 89.1 (85.5-92.7) & $94.6(91.9-97.3)$ \\
\hline & Having work or other daytime activities ( $<65$ years) & 523 & $94.4(91.6-97.2)$ & $98.1(96.4-99.8)$ \\
\hline & Having paid work ( $<65$ years) & 503 & $60.3(54.3-66.3)$ & $30.1(24.3-35.9)$ \\
\hline & $\begin{array}{l}\text { Having work or other daytime activities not specially } \\
\text { for people with ID }\end{array}$ & 572 & $17.0(12.7-21.3)$ & $12.2(8.4-16.1)$ \\
\hline \multirow[t]{5}{*}{ Social contact with } & Family & 559 & $66.1(60.6-71.5)$ & $73.8(68.5-79.1)$ \\
\hline & Friends & 544 & $43.5(37.7-49.2)$ & $28.7(23.2-34.3)$ \\
\hline & Friends without ID & 530 & $15.3(11.1-19.4)$ & $8.9(5.1-12.2)$ \\
\hline & Neighbours & 550 & $9.7(6.2-13.1)$ & $14.6(10.3-18.9)$ \\
\hline & Neighbours without ID & 528 & $6.3(3.5-9.1)$ & $6.6(3.5-9.8)$ \\
\hline \multirow[t]{2}{*}{ Leisure activities } & Visit sometimes a restaurant/café/cinema/theatre & 557 & $68.3(62.9-73.7)$ & $75.7(70.5-80.8)$ \\
\hline & Leisure activities not specially for people with ID & 501 & $34.9(29.2-40.6)$ & $41.2(34.7-47.6)$ \\
\hline
\end{tabular}

Bold denotes statistical significance $(P<0.05)$ determined by chi square analysis.

ID, intellectual disability. 
Dusseljee, J.C.E., Rijken, P.M., Cardol, M., Groenewegen, P.P., Curfs, L.M.G. Participation in daytime activities among people with mild or moderate intellectual disability. Journal of Intellectual Disability Research: 2011, 55(1), 4-18

Table 7 Percentages of community participation for people living in non-campus and campus settings separately

\begin{tabular}{|c|c|c|c|c|}
\hline Variable & Indicator & $n$ & $\begin{array}{l}\text { Non-campus } \\
\text { settings } \\
(n=517) \\
\%(95 \% \mathrm{Cl})\end{array}$ & $\begin{array}{l}\text { Campus } \\
\text { settings } \\
(n=I I 2) \\
\%(95 \% \mathrm{Cl})\end{array}$ \\
\hline \multirow[t]{4}{*}{ Employment status } & Having work or other daytime activities & 629 & $91.3(88.9-93.7)$ & $93.8(89.2-98.3)$ \\
\hline & Having work or other daytime activities (<65 years) & 573 & $95.8(94.0-97.6)$ & $99.0(97.0-1.01)$ \\
\hline & Having paid work ( $<65$ years) & 551 & $52.6(48.0-57.2)$ & $23.1(|4.3-3| .9)$ \\
\hline & $\begin{array}{l}\text { Having work or other daytime activities not specially } \\
\text { for people with ID }\end{array}$ & 629 & $15.3(12.2-18.4)$ & $8.9(3.6-14.3)$ \\
\hline \multirow[t]{5}{*}{ Social contact with } & Family & 616 & $68.0(63.9-72.0)$ & $70.1(61.4-78.8)$ \\
\hline & Friends & 601 & $37.2(33.0-4 \mid .5)$ & $33.7(24.5-42.8)$ \\
\hline & Friends without ID & 586 & $12.9(9.9-15.9)$ & $8.1(2.7-13.5)$ \\
\hline & Neighbours & 607 & $10.8(8.1-13.5)$ & $17.9(10.6-25.3)$ \\
\hline & Neighbours without ID & 583 & $7.8(5.4-10.2)$ & $1.1(-1.0-3.2)$ \\
\hline \multirow[t]{2}{*}{ Leisure activities } & Visit sometimes a restaurant/café/cinema/theatre & 614 & $70.2(66.2-74.2)$ & $73.2(64.7-81.6)$ \\
\hline & Leisure activities not specially for people with ID & 571 & $36.2(26.2-46.3)$ & $36.0(31.7-40.4)$ \\
\hline
\end{tabular}

Bold denotes statistical significance $(P<0.05)$ determined by chi square analysis.

ID, intellectual disability. 